\title{
Fentanyl Measurement
}

National Cancer Institute

\section{Source}

National Cancer Institute. Fentanyl Measurement. NCI Thesaurus. Code C147338.

The determination of the amount of fentanyl present in a sample. 